Tjalling C. Koopmans Research Institute

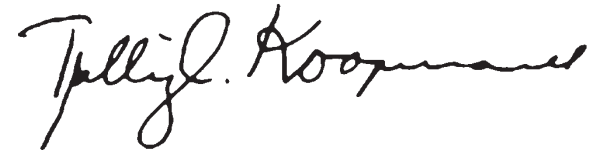

Discussion Paper Series nr: 11-12

\title{
Central Bank Transparency, the Accuracy of Professional Forecasts, and Interest Rate Volatility
}

Menno Middeldorp 


\section{Tjalling C. Koopmans Research Institute Utrecht School of Economics \\ Utrecht University}

Janskerkhof 12

3512 BL Utrecht

The Netherlands

telephone $\quad+31302539800$

fax +31302537373

website www.koopmansinstitute.uu.nl

The Tjalling C. Koopmans Institute is the research institute and research school of Utrecht School of Economics.

It was founded in 2003, and named after Professor Tjalling C. Koopmans, Dutch-born Nobel Prize laureate in economics of 1975.

In the discussion papers series the Koopmans Institute publishes results of ongoing research for early dissemination of research results, and to enhance discussion with colleagues.

Please send any comments and suggestions on the Koopmans institute, or this series to J.M.vanDort@uu.nl

ontwerp voorblad: WRIK Utrecht

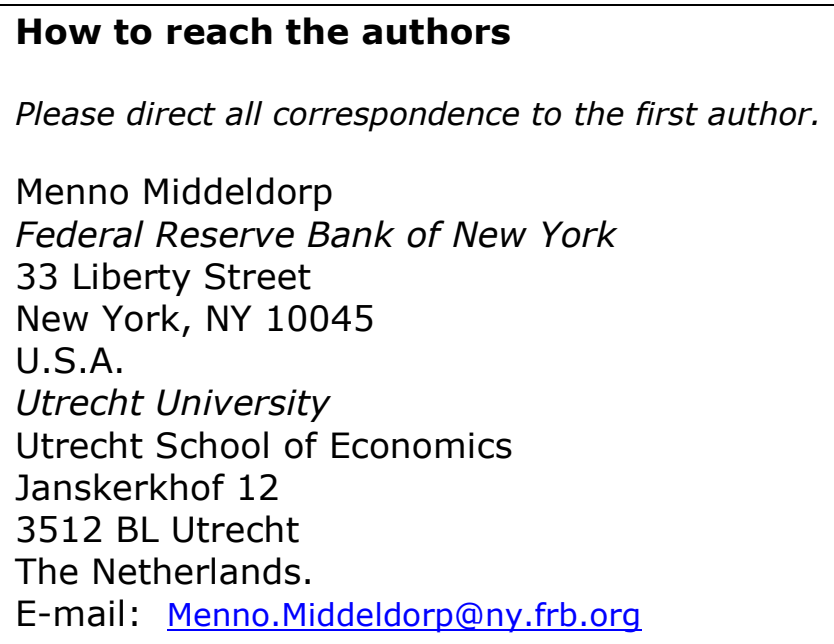




\title{
Central Bank Transparency, the Accuracy of Professional Forecasts, and Interest Rate Volatility
}

\author{
Menno Middeldorp \\ Federal Reserve Bank NY
}

U.S.A.

Utrecht School of Economics

Utrecht University

July 2011

Federal Reserve Bank of New York Staff Reports, no. 496

\begin{abstract}
Central banks worldwide have become more transparent. An important reason is that democratic societies expect more openness from public institutions.

Policymakers also see transparency as a way to improve the predictability of monetary policy, thereby lowering interest rate volatility and contributing to economic stability. Most empirical studies support this view. However, there are three reasons why more research is needed. First, some (mostly theoretical) work suggests that transparency has an adverse effect on predictability. Second, empirical studies have mostly focused on average predictability before and after specific reforms in a small set of advanced economies. Third, less is known about the effect on interest rate volatility. To extend the literature, I use the Dincer and Eichengreen (2007) transparency index for twenty-four economies of varying income and examine the impact of transparency on both predictability and market volatility. I find that higher transparency improves the accuracy of interest rate forecasts for three months ahead and reduces rate volatility.
\end{abstract}

Keywords: Central bank communication, interest rate forecasts, central bank transparency, financial market efficiency

JEL classification: D83, E47, E58, G14

\section{Acknowledgements}

The author gratefully acknowledges the support of the Institute for Monetary Research of the Hong Kong Monetary Authority (HKMA), where most of the research was conducted in the context of a doctoral dissertation for Utrecht University. Thanks also to Qianying Chen, Deborah Perelmuter, Matthew Raskin, Stephanie Rosenkranz, and participants at an HKMA seminar for useful questions and comments. Special thanks to Clemens Kool for extensive comments on several drafts. The views expressed in the paper are those of the author and do not necessarily reflect the position of the Federal Reserve Bank of New York or the Federal Reserve System. Any errors or omissions are the responsibility of the author.

This paper presents preliminary findings and is being distributed to economists and other interested readers solely to stimulate discussion and elicit comments. The views expressed in this paper are those of the author and are not necessarily reflective of views at the Federal Reserve Bank of New York or the Federal Reserve System. Any errors or omissions are the responsibility of the author. 


\section{Overview}

Central banks worldwide have become considerably more transparent about monetary policy, including defining their goals, explaining decisions, releasing economic forecasts and providing guidance about future policy. Between 1998 and 2005, 89 of the 100 countries in the Dincer and Eichengreen (2007) index show an increase in transparency and none a decline. An important reason is that (the increased number of) democratic societies expect more openness from public institutions. Another motivation for greater transparency is a reduction in monetary policy surprises to thereby reduce accompanying financial market and economic volatility. Along these lines, Bernanke (2004) asserts that, "clear communication helps to increase the near-term predictability of [central bank] ${ }^{1}$ rate decisions, which reduces risk and volatility in financial markets and allows for smoother adjustment of the economy to rate changes." This paper focuses on the benefits Bernanke describes, by examining transparency's impact both on predictability and interest rate volatility.

As discussed in the literature review in Section 2, Although straightforward intuition and standard financial market theory suggest that transparency should enhance predictability, this has been challenged by some theoretical and experimental research, that shows that under some circumstances transparency can reduce the use of private information and thereby actually damage predictability.

Nevertheless, a considerable body of empirical research suggests that transparency improves predictability. The focus in empirical work has largely been on fixed income markets, for at least three reasons. First, they provide a readily available measure of monetary policy expectations. Second, they provide the most immediate avenue through which the central bank's own interest rates affect the economy. Third, central banks are often concerned with the volatility of interest rates and thus averse to surprising markets, as the quote above illustrates.

Three approaches have been used to assess the impact of greater transparency on predictability. First, testing the extent to which market prices react to central bank decisions, second, examining forecast errors of expectations priced into the yield curve or futures and third, studying the accuracy of predictions by professional forecasters.

Each approach has its own advantages and disadvantages. In this paper I use private sector forecasts of money market interest rates for four reasons. First, these represent a straightforward measure of expectations. Second, they are available for a broad set of countries. Third, they are available for fore-

\footnotetext{
${ }^{1}$ Originally "FOMC" for the Federal Open Market Committee, the body that sets US monetary policy; clearly the same reasoning applies to any other central bank.
} 
cast horizons out to a year. Fourth and importantly, it is possible to observe individual forecasts.

Despite the significant number of papers, there is still room for improvement in the empirical literature. Most studies only examine a limited number of advanced countries. They do this largely by comparing average predictability before and after specific reforms in communication policy. As a result, there is no real understanding of the relationship between varying levels of transparency (across time and space) and corresponding variations in predictability. The research presented in this paper addresses these gaps in the literature by utilizing the Dincer and Eichengreen (2007) index along with professional interest rate forecasts to study varying levels of transparency across 24 countries with differing levels of economic development. Because one goal of improving monetary policy predictability is to reduce financial market and economic volatility, this paper also examines the impact of transparency on interest rate volatility.

To establish a relationship between transparency, predictability and interest rate volatility requires measures of all three. In Section 3, I give a detailed description of datasets that can be used to do this. To measure transparency I employ the Dincer and Eichengreen (2007) index, which essentially counts the number of transparency enhancing institutions of each central bank. To measure predictability I use the error of professional interest rate forecasts at both three and twelve month horizons. To measure interest rate volatility I use the historic standard deviation of the same interest rates.

Section 4 describes formally how public information could impact forecasts of interest rates and interest rate volatility. If an increase in transparency only improves public information then it will result in individual forecasts that become more accurate. However, if transparency has a negative impact on private information, as the theoretical and experimental research discussed below suggests, it could also lead to higher errors. Theoretically, market volatility behaves similarly to predictability, more public information should dampen volatility unless it hampers private information.

As shown in Section 5, simple graphs and panel regression results suggest that transparency enhances predictability. Forecast errors decline significantly at the three month horizon, but not at twelve months ahead. Transparency also lowers volatility. Overall the evidence suggests that transparency can indeed serve the goal outlined by Bernanke (2004), i.e. improving predictability helps to foster lower interest rate volatility. 


\section{Review of the literature on predictability}

The literature on central bank transparency and communication has grown rapidly over the last decade and now consists of hundreds of papers and articles. Different angles have been pursued. Many papers examine the implications of transparency in theoretical macroeconomic models. Others examine empirically if transparency has influenced inflation and other macroeconomic variables. The impact of transparency on the financial markets has also been an important theme in the literature. Especially around the turn of the century, many articles examined if central bank communication had some impact on the financial markets, generally concluding that it does. The question addressed here goes a step further, asking whether transparency improves the predictability of monetary policy in the financial markets. This section reviews the theoretical, experimental and empirical evidence to date and highlights gaps in the literature that are addressed by research described in the remainder of the paper. Blinder, Ehrmann, Fratzscher, de Haan and Jansen (2008) and van der Cruijsen and Eijffinger (2007) offer broader overviews of the literature on transparency.

\section{$2.1 \quad$ Theory}

Intuitively, one would expect better public information to improve market functioning, in the sense that financial markets become better at predicting the outcome of unrealized fundamentals. This is true in a basic rational expectations asset market model with exogenous public and private information. ${ }^{2}$ Under different assumptions or models, however, better public information can hamper market functioning.

Probably the best known example is Morris and Shin (2002). They present a model where the profits of individual agents depend not only on fundamental values but also on the expectations of others (clearly an issue in any market where assets can be sold before the realization of their fundamental value). Under these circumstances a sufficiently clear signal from the central bank can act as a coordinating point that could distract market participants from their private information and possibly fundamentals. Svensson (2006) argues that this conclusion is only valid for the unlikely situation where public signals are less precise than private information. However, Demertzis and Hoeberichts (2007) add costly information acquisition to Morris and Shin (2002)'s model and find that it strengthens their result.

Another theoretical model by Dale, Orphanides and Osterholm (2008) demonstrates that if the private sector is not able to learn the precision of the central bank's information, it may overreact to central bank communication. Kool et al.

\footnotetext{
${ }^{2}$ See Kool, Middeldorp and Rosenkranz (2011), where the case of exogenous private information is equivalent to holding the fraction of informed traders constant.
} 
(2011) find that public information can crowd out investment in private information, which hampers predictability, a conclusion supported by the experimental work of Middeldorp and Rosenkranz (2011).

\subsection{Empirical studies}

Many empirical research papers have tried to assess if transparency improves the predictability of monetary policy in the financial markets. ${ }^{3}$ The general approach is to select a watershed communication reform and test the difference between predictability before and afterwards. US studies typically use the first announcement of the Federal Open Market Committee's (FOMC) rate decisions in February 1994, while for other countries the introduction of an inflation target, with its accompanying communication tools, is used. One can measure predictability in at least three ways. The first is to ascertain how surprised markets are by policy decisions. The second extracts expectations from the yield curve or futures to see how accurate they are. The third uses professional forecasts of interest rates. Taken together the evidence to date suggests that transparency improves predictability.

The first approach to assessing the predictability of monetary policy involves examining market movements close to policy decisions. Little reaction in money market rates following a policy rate change suggests that it has been priced in and that policy is predictable. Money market movements prior to the decision in the same direction as the rate change can be interpreted as anticipating the move. Swanson (2006) finds that US interest rates show less reaction to Fed decisions over the period where the Fed reformed its communication policy. Holmsen, Qvigstad, Øistein Røisland and Solberg-Johansen (2008) find lower volatility on the days the Norges Bank announced its decisions after it started to release forecasts of its own interest rates. Murdzhev and Tomljanovich (2006) and Coppel and Connolly (2003) show that policy changes are better anticipated in, respectively, six and eight advanced economies. Although such an approach is fairly intuitive and clear cut, its disadvantage is that it only provides a measure of market expectations between meetings and at the time of rate announcements. Communication reforms that allow market interest rates to anticipate monetary policy earlier than one meeting ahead can't be identified.

A second method is to measure market expectations of monetary policy and examine how accurate these are. Typically expectations are either extracted from the yield curve or futures data. Here too, findings suggest that

\footnotetext{
${ }^{3}$ A related strand of the literature does not address predictability in the financial markets but examines the usefulness of central bank communication in contructing forecasts of monetary policy. Some studies have simply asked if communications contain predictive power in itself; examples include Mizen (2009) and Jansen and de Haan (2009). Other studies examine if communication is useful in improving models that forecast monetary policy, such as the Taylor rule; recent examples are Sturm and de Haan (2009) for the ECB and Hayo and Neuenkirch (2009) for the FOMC.
} 
transparency improves predictability. Rafferty and Tomljanovich (2002) and Lange, Sack and Whitesell (2003) find better accuracy for the US Treasury yield curve. Lildholdt and Wetherilt (2004) use a term structure model to show an improvement in the predictability of UK monetary policy. Similarly, Tomljanovich (2004) extracts expectations from bond yield curves and finds that forecast errors decline in seven advanced economies after transparency reforms.

Regarding futures rates, Swanson (2006) and Carlson, Craig, Higgins and Melick (2006) find that the Fed funds futures are better able to predict US monetary policy after communication reforms. Kwan (2007) concludes that forward looking language or guidance, introduced in 2003, has helped to lower the average error between the Fed funds futures and the actual outcome of the Fed funds rate.

The disadvantage of using bond market expectations, is that such estimates are likely to be biased. The failure of the expectations hypothesis for the Treasury yield curve is a well-documented empirical result (e.g. Cochrane and Piazzesi (2005), Campbell and Shiller (1991), Stambaugh (1988), Fama and Bliss (1987)). Risk premiums on interest rates are positive on average and timevarying. Sack (2004) and Piazzesi and Swanson (2008) show that Fed funds futures rates also include risk premiums, particularly at longer maturities. Piazzesi and Swanson (2008) demonstrate how to adjust Fed funds futures rates for time-varying risk premiums using business cycle data. Middeldorp (2011) contributes to the literature on transparency by applying their correction to the question of the accuracy of the Fed funds futures.

A third approach is to use predictions by professional forecasters. These are a direct measure of expectations, without risk premiums, and also allow one to observe individual forecasts. There are several studies that look at US interest rates. Swanson (2006) finds an improvement in the accuracy of private sector interest rate forecasts. Berger, Ehrmann and Fratzscher (2006) find that communication reduces the disparity of Fed funds target rate predictions produced by forecasters from different locations. Hayford and Malliaris (2007) and Bauer, Eisenbeis, Waggoner and Zha (2006) find declining dispersion in US T-bill forecasts. Regarding other central banks, Mariscal and Howells (2006b) find a growing dispersion of private sector forecasts of Bundesbank and ECB monetary policy up to 2005, a result which runs counter to that for most others studies, including that of their own (2006b) research for the Bank of England.

Several multi-country studies use professional forecasts, but they generally focus on economic rather than interest rate forecasts. Johnson (2002) shows a decline in inflation forecasts, but not in errors or variance, in an eleven country panel. Crowe (2006) finds a convergence of inflation forecasts for eleven inflation targeters. Crowe and Meade (2008) demonstrate a convergence of inflation forecasts in line with increasing transparency as measured by an index. Cecchetti and Hakkio (2009), on the other hand, do not find convincing evidence of a reduction in the dispersion of inflation forecasts in a sample of 15 countries. 
Ehrmann, Eijffinger and Fratzscher (2010) use various measures of central bank transparency to show a convergence of professional forecasts of both economic variables and interest rates in twelve advanced economies. To my knowledge, there are no studies like the one presented in this paper, that focus on interest rate forecasts using multi-country panel data.

A disadvantage of professional forecasts versus the expectations embedded in interest rates is that it is not obvious that they are relevant to the transmission of monetary policy. It is, nevertheless, likely that they both reflect and influence monetary policy expectations. Large financial institutions are the most common employers of professional forecasters and their views are actively dispersed to market participants and widely reported on in the press.

Although there is a significant number of empirical studies, they are limited in scope, both in their measure of transparency and geography. The vast majority of the empirical research discussed above only shows that the average predictability was higher after a particular communication reform than it was before. This provides only a binary measure of transparency that gives little sense of how much transparency has improved. Regarding geographic scope, studies have been conducted for a limited number of advanced economies, typically one country at a time. To address these issues I use a measure of transparency with a higher resolution, namely the Dincer and Eichengreen (2007) index, which uses a 15 point scale. Combined with the available data on interest rate forecasts, this produces a panel of 24 countries of varying levels of income, which provides much greater geographic scope than earlier research. 


\section{Data}

To establish the connection of transparency to interest rate predictability and volatility, one needs adequate measures of all three. I use the Dincer and Eichengreen (2007) index to measure transparency. It grades central banks according to the different types of information disclosed. Its main advantage is that it covers a larger set of countries and periods than earlier measures.

Predictability is measured by the absolute error between private sector money market forecasts reported by Consensus Economics and realized market rates. The advantages and disadvantages of using professional forecasts were discussed in the literature review.

To examine if transparency also impacts the volatility of interest rates, I also incorporate the standard deviation of interest rates into the dataset.

Transparency is unlikely to be the only determinant of either predictability or volatility. Therefore, to control for overall perceptions of risk I utilize the commonly used financial risk indices of the PRS Group.

\subsection{Transparency index}

Different measures of transparency have been assembled and corresponding data collected by various researchers. The approach was pioneered by Eijffinger and Geraats (2006), who measure transparency by scoring central banks on a checklist of 15 different types of disclosure, which are grouped into five categories: political, economic, procedural, policy and operational (see the Appendix). Their measure of transparency is based on the simple idea that more types of disclosure represent greater transparency. A disadvantage is that the quality of the information provided is neglected. On the other hand, precisely by avoiding additional interpretation it is possible to create an objective measure of transparency over a wide variety of central banks.

Eijffinger and Geraats (2006) only have data available for nine advanced economies and for just the years 1998 and 2002. Crowe and Meade (2008) assemble data for 37 countries, following the same approach. Their data, however, is only available for 1998 and 2006, but not in between. Dincer and Eichengreen (2007) also employ the same method but gather data for a hundred countries for every year between 1998 and 2005. The scope of their dataset clearly surpasses other data sources, which is why it is used in this paper. However, due to the necessary availability of both the transparency data and the surveys of professional forecasts discussed below, only 24 of the hundred countries studied by Dincer and Eichengreen (2007) can be used. 
Dincer and Eichengreen (2007) compare the disclosure checklist to the practice of central banks as documented on their websites and in their statutes, annual reports and other published documents. For some items half points are awarded. The approach followed results in a score for each central bank of between 0 and 15 for each year. Where reforms were introduced during the year, the score is based on the disclosures that existed during most of the year.

Levels of transparency vary greatly over the sample studied in this paper, both over space and time. India only scores a 2 on the index compared to 13.5 for New Zealand in 2005 (see Figure 1 and Table 1). In between there is no concentration at any particular level of transparency. Lower-income economies tend to have lower levels of transparency, but this is not a hard-and-fast rule; the Czech Republic and Hungary are more transparent than the US while Norway is as transparent as Indonesia. Transparency has increased substantially over the majority of the countries studied and no country saw a decrease in transparency (see Figure 1 and Table 1). Although the three nations that show the largest increase in transparency are lower-income economies, the rates of improvement do not seem to be strongly associated with income levels. 


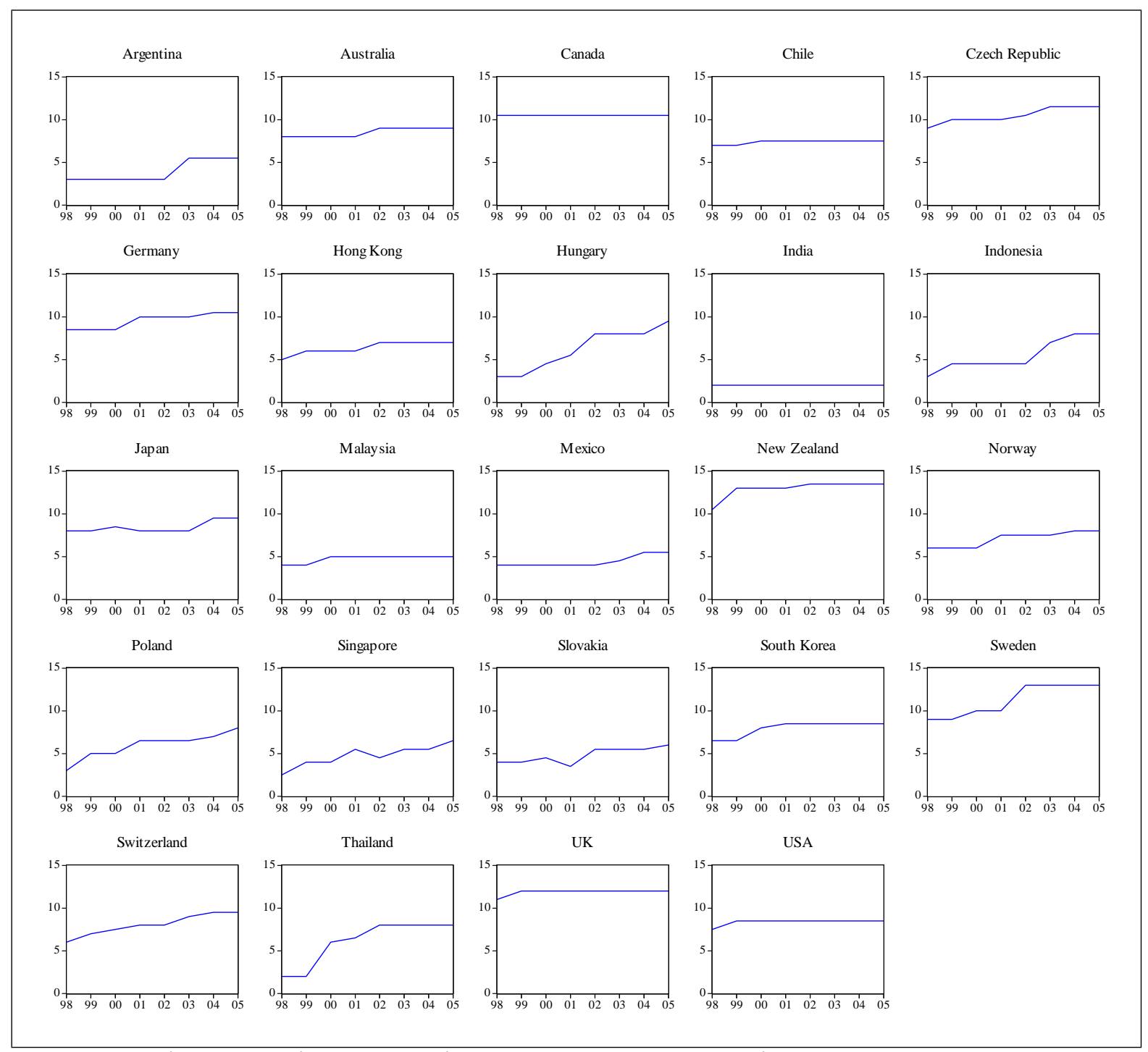

Figure 1: Dincer and Eichengreen transparency index per country 


\begin{tabular}{|c|c|c|c|c|c|c|c|}
\hline Country & GDP per capita & Transparency & Transparency & Years & & Forecasters & Yrs $\times$ Frestrs \\
\hline & (PPP, 2002) & First Year & Final Year & & & & \\
\hline USA & 36.3 & 7.5 & 8.5 & $98-05$ & 8 & 38 & 304 \\
\hline Norway & 33.0 & 6.0 & 8.0 & $98-05$ & 8 & 19 & 152 \\
\hline Switzerland & 32.0 & 6.0 & 9.5 & $98-05$ & 8 & 18 & 144 \\
\hline Canada & 29.3 & 10.5 & 10.5 & $98-05$ & 8 & 25 & 200 \\
\hline Japan & 28.7 & 8.0 & 9.5 & $98-05$ & 8 & 38 & 304 \\
\hline Hong Kong & 27.2 & 5.0 & 7.0 & $98-05$ & 8 & 26 & 208 \\
\hline Australia & 26.9 & 8.0 & 9.0 & $98-05$ & 8 & 27 & 216 \\
\hline Germany & 26.2 & 8.5 & 10.5 & $98-05$ & 8 & 43 & 344 \\
\hline Sweden & 26.0 & 9.0 & 13.0 & $98-05$ & 8 & 22 & 176 \\
\hline UK & 25.5 & 11.0 & 12.0 & $98-05$ & 8 & 42 & 336 \\
\hline Singapore & 25.2 & 2.5 & 6.5 & & 8 & 28 & 224 \\
\hline N. Zealand & 20.1 & 10.5 & 13.5 & $98-05$ & 8 & 20 & 160 \\
\hline Korea, S. & 19.6 & 6.5 & 8.5 & $98-05$ & 8 & 27 & 216 \\
\hline Czech Rep. & 15.3 & 9.0 & 11.5 & $98-03$ & 6 & 32 & 192 \\
\hline Hungary & 13.3 & 3.0 & 8.0 & $98-03$ & 6 & 25 & 150 \\
\hline Slovakia & 12.4 & 4.0 & 5.5 & $98-03$ & 6 & 18 & 108 \\
\hline Argentina & 10.5 & 3.0 & 5.5 & $01-04$ & 4 & 24 & 96 \\
\hline Chile & 10.1 & 7.5 & 7.5 & '01 - 04 & 4 & 22 & 88 \\
\hline Poland & 9.7 & 3.0 & 6.5 & $98-03$ & 6 & 32 & 192 \\
\hline Mexico & 8.9 & 4.0 & 5.5 & '01 - 04 & 4 & 29 & 116 \\
\hline Malaysia & 8.8 & 4.0 & 5.0 & $98-05$ & 8 & 33 & 264 \\
\hline Thailand & 7.0 & 2.0 & 8.0 & $98-05$ & 8 & 27 & 216 \\
\hline Indonesia & 3.1 & 3.0 & 8.0 & $98-05$ & 8 & 27 & 216 \\
\hline India & 2.6 & 2.0 & 2.0 & $98-05$ & 8 & 26 & 208 \\
\hline Average & 19.1 & 6.0 & 8.3 & & & 28 & 201 \\
\hline High & 36.3 & 11.0 & 13.5 & & & 43 & 344 \\
\hline Low & 2.6 & 2.0 & 2.0 & & & 18 & 88 \\
\hline
\end{tabular}

Table 1: GDP per capita, transparency and sample characteristics 


\subsection{Professional forecasts error and interest rate volatility}

Several sources are available for professional interest rate forecasts. Information services Bloomberg and Reuters conduct regular surveys of professional forecasters as do central banks themselves, such as the Philadelphia Federal Reserve and the ECB. Consensus Economics, however, surveys private sector economic forecasters in a standardized way over a larger set of countries than other sources.

Consensus Economics collects forecasts for short-term interest rates for a variety of countries, typically of a three month maturity, either from government bills, interbank rates or another benchmark rate. For some economies interest rate forecasts are unavailable or have a different maturity. These countries are excluded from the sample. During the sample period, the three month maturity is short enough that it can be considered to be essentially driven by monetary policy and thus serves as the best available indicator of policy rates for which forecasts are available for a wide set of countries.

Survey participants for a particular country are asked for their forecasts of the three month money market rate of that country for both three and twelve months in the future. More specifically, every month survey participants are asked for their interest rate forecasts for the end of the third subsequent calendar month and the end of the same calendar month in the following year. For example, the July 1999 survey presents forecasts for the end of October 1999 and the end of July 2000.

Consensus Economics does not collect interest rate forecasts for the Eurozone as a whole, but does so for several constituent countries. There is, however, only one interbank rate for the entire monetary union. ${ }^{4}$ Using several Euro-zone countries in the panel would create multiple observations regarding only the European Central Bank. Instead, I use forecasts for just Germany. Not only is Germany the largest economy in the Eurozone, it has by far the largest number of forecasters.

The Consensus Economics data used are extracted from the hard copy booklets at the Hong Kong Monetary Authority library. The "Eastern Europe Consensus Forecasts" were only available between 1998 and 2003 and the "Latin American Consensus Forecasts" between 2001 and April 2004. Over the sample the Consensus Economics surveys were conducted every month except for Eastern Europe, for which the surveys were conducted every second month. The closing date for the survey ranges from 8th to 14th day of the month for industrialized and Asia-Pacific countries and from the 15th to 21st for Eastern European and Latin American countries. To match the Dincer and Eichengreen (2007) data, I use the survey results only for the month closest to the middle

\footnotetext{
${ }^{4}$ Except for the three month forecasted in 1998, the year before the euro was introduced.
} 
of the year. This is July in all cases except for Argentina, Chile and Mexico in 2004 where I use April.

Forecasts are collected by individual organization per country. These include a variety of non-governmental entities such as independent or university affiliated research institutes and economic consulting firms. The majority, however, are financial institutions varying from domestic and regional commercial banks to global investment banks. There are 331 different organizations providing forecasts, with only 59 of these providing forecasts for more than one country. In the cross-section forecasters are treated separately per country (i.e. a British bank forecasting both the UK and the USA would count as two separate forecasters) resulting in a total of 658 . Because forecasters rarely provide forecasts for all years, the sample contains only 2236 forecasts for three months ahead and 2191 forecasts for one year ahead.

To determine their accuracy, forecasts need to be compared to outcomes three and twelve months down the road. To do so, data for the forecasted interest rates were gathered from EcoWin, CEIC and Bloomberg. The absolute difference between the individual forecast at $t$ and the actual outcome at $t+$ 3 months and $t+12$ months forms a direct measure of the accuracy of the individual forecasts.

To measure the volatility of interest rates I calculate the standard deviation of interest rates using daily data for the three subsequent calendar months (typically first day of August until the last day of October) and the following twelve calendar months (typically first day of August to the last day of July the following year). There are numerous forecasters per country, so the number of individual forecast errors (2236 and 2191, as above) greatly exceeds the number of observations for the volatility measure (172).

To graphically illustrate the general development of forecast errors per country I also calculate the absolute difference between the average forecast (i.e. the "consensus" of forecasters) and the actual interest rate at $t+3$ months and $t+12$ months. Results are charted in Figure 2. As one might expect, the 3 month errors are generally smaller than the 12 month errors. Errors and their variation are particularly large for countries that experienced financial and economic crisis during this period, Argentina in particular dramatically stands out. The 1998 financial market crisis affects several countries in the sample particularly Asian and developing economies. The consequences of this shock vary substantially, however, with peak errors varying from 0.5\%-point for Japan to $20 \%$-point for Indonesia. The 2001 recession is also visible for a minority of advanced economies. Overall, forecast errors vary substantially per country (also see Table 2) and show different variations over time. 


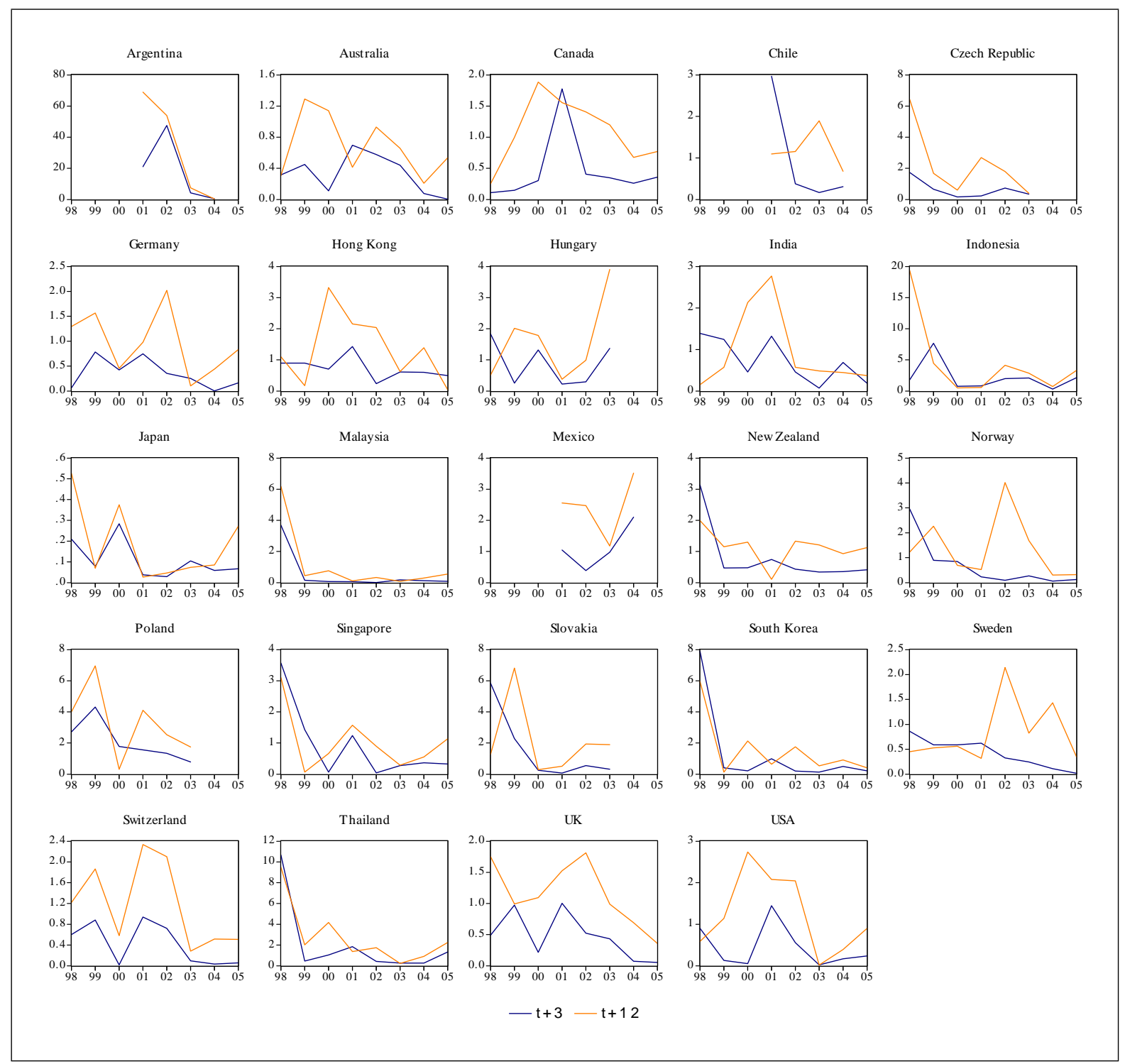

Figure 2: Absolute error of average forecast (\%-point) 
Figure 3 shows that patterns in the volatility data are analogous to those described for the forecast errors. Here too the Asia crisis is visible, and again there are substantial differences in its impact. As with the errors data, differences between countries are large, both in terms of volatility levels (See Table 2) and variations over time.

The main difference in Figure 3 versus Figure 2 is that the three month and twelve month volatilities appear closer together than the corresponding errors for these time frames. Given that the standard deviation of daily interest rates is, by definition, calculated over a sample period, this is not surprising for two reasons. First, the three month sample overlaps a quarter of the twelve month sample. Second, the average date of the samples are closer together, i.e. $t+1.5$ months and $t+6$ months versus the $t+3$ and $t+12$ months for the forecast errors. 


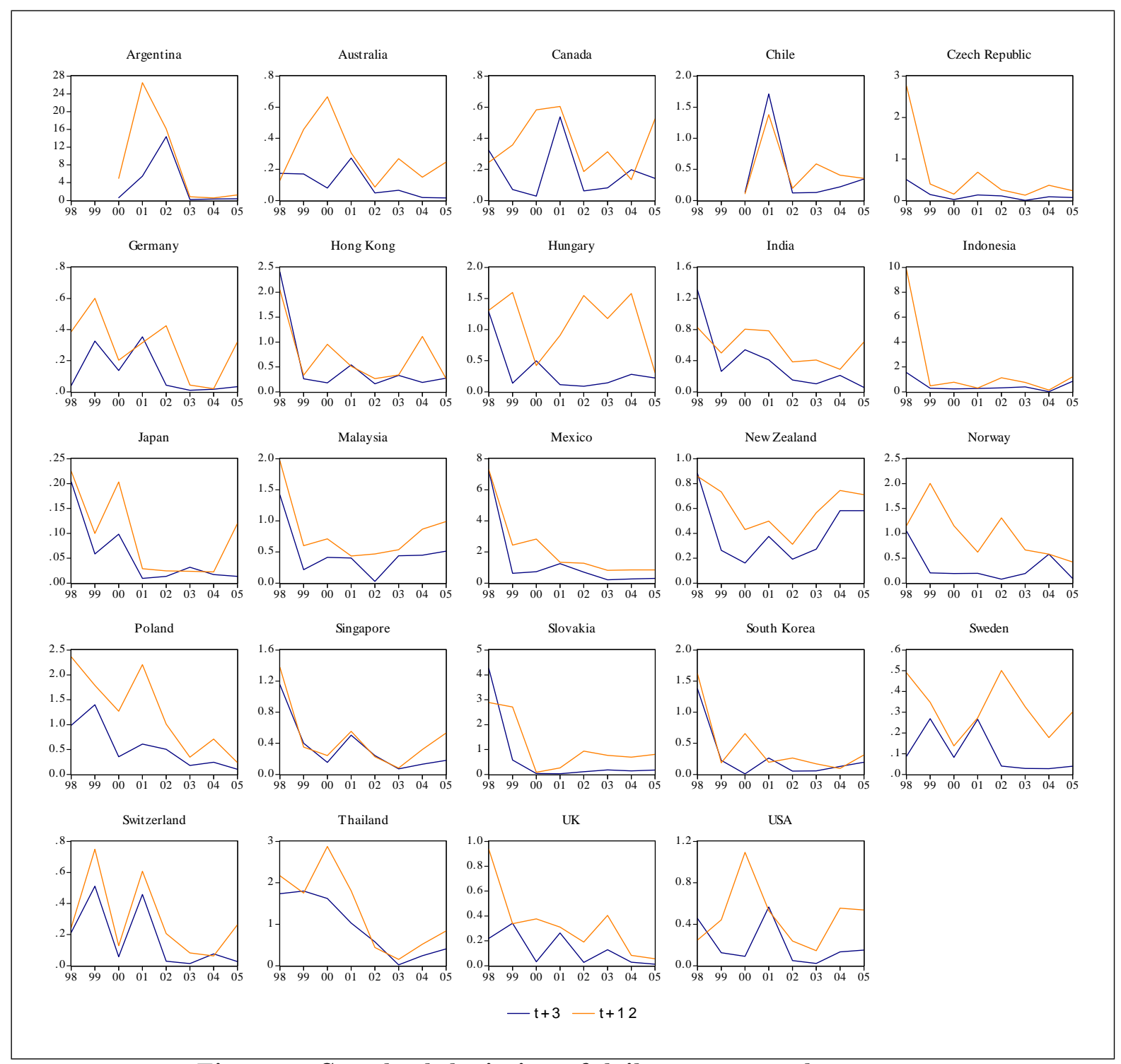

Figure 3: Standard deviation of daily money market rates 
Forecast errors and financial market volatility reflect more than just the transparency of the central bank. Both are affected by overall predictability of interest rates due to the economic and financial risks that affect them. To control for country risk in the analysis below, I utilize the economic and financial risk indicators of the International Country Risk Guide of the Political Risk Services (PRS) Group. According to Linder and Santiso (2002) these ratings are used by around four-fifths of the companies on Fortune magazine's list of largest multinationals. The financial and economics risk ratings are constructed with objective data that are weighed together according to predefined scales. ${ }^{5}$ Higher ratings indicate less risk. The economic risk rating is constructed from GDP per head, real GDP growth, inflation, general government balance as a percentage of GDP and current account as a percentage of GDP. The components of financial risk are foreign debt as a percentage of GDP, foreign debt service as a percentage of exports of goods and services, current account as percentage of exports of goods and services, official reserves import cover and year-on-year exchange rate movement. Essentially the risk ratings provide a standardized and parsimonious way to reflect a variety of economic and financial fundamentals that affect risk. A downside may be that the ratings may not reflect differences in the ability of countries to maintain government and current account deficits or carry debt, see for example the relatively low ratings of some developed countries in Figure 4 and Table 2.

\footnotetext{
${ }^{5}$ See http://www.prsgroup.com/PDFS/icrgmethodology.pdf.
} 


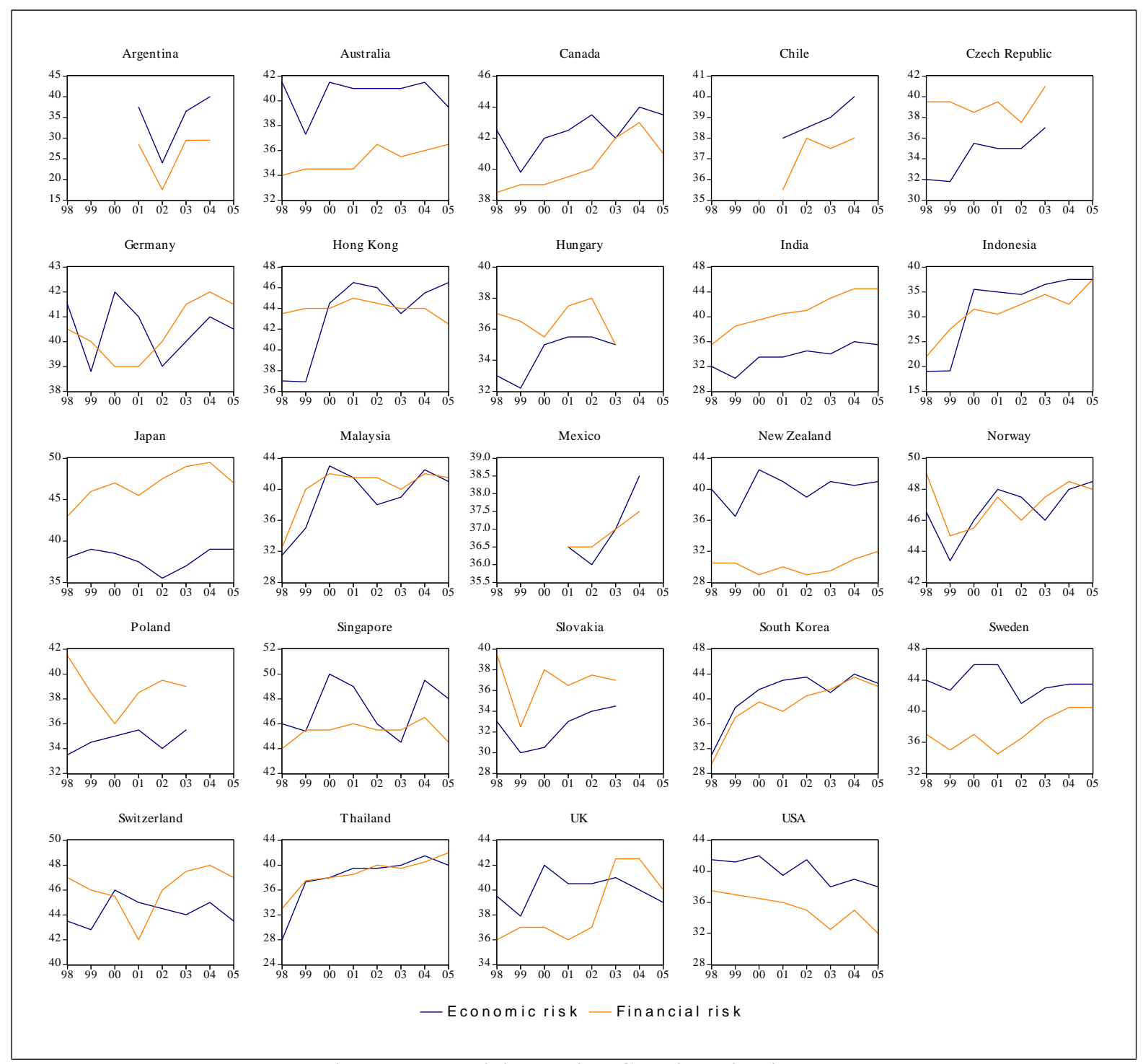

Figure 4: Political Risk Services indices 


\begin{tabular}{|c|c|c|c|c|c|c|}
\hline Country & Average & Average & Average & Average & Average & Average \\
\hline & |Error| & |Error| & Volatility & Volatility & Risk Rating & Risk Rating \\
\hline & $\mathbf{t}+3$ & $\mathrm{t}+12$ & $t$ to $t+3$ & $t$ to $t+12$ & Economic & Financial \\
\hline USA & 0.4 & 1.2 & 0.2 & 0.5 & 40.1 & 35.2 \\
\hline Norway & 0.7 & 1.4 & 0.3 & 1.0 & 46.7 & 47.1 \\
\hline Switzerland & 0.4 & 1.2 & 0.2 & 0.3 & 44.3 & 46.1 \\
\hline Canada & 0.5 & 1.1 & 0.2 & 0.4 & 42.5 & 40.3 \\
\hline Japan & 0.1 & 0.2 & 0.1 & 0.1 & 37.9 & 46.8 \\
\hline Hong Kong & 0.7 & 1.4 & 0.5 & 0.7 & 43.3 & 43.9 \\
\hline Australia & 0.3 & 0.7 & 0.1 & 0.3 & 40.5 & 35.3 \\
\hline Germany & 0.3 & 1.0 & 0.1 & 0.3 & 40.5 & 40.4 \\
\hline Sweden & 0.4 & 0.8 & 0.1 & 0.3 & 43.7 & 37.5 \\
\hline UK & 0.5 & 1.2 & 0.1 & 0.3 & 40.0 & 38.5 \\
\hline Singapore & 0.9 & 1.0 & 0.4 & 0.5 & 47.3 & 45.4 \\
\hline N. Zealand & 0.8 & 1.1 & 0.4 & 0.6 & 40.2 & 30.2 \\
\hline Korea, S. & 1.3 & 1.6 & 0.3 & 0.4 & 40.6 & 38.9 \\
\hline Czech Rep. & 0.6 & 2.3 & 0.1 & 0.6 & 34.4 & 39.3 \\
\hline Hungary & 0.9 & 1.6 & 0.3 & 1.1 & 34.4 & 36.6 \\
\hline Slovakia & 1.6 & 2.1 & 0.7 & 1.1 & 32.5 & 36.8 \\
\hline Argentina & 18.3 & 32.7 & 3.6 & 8.4 & 34.5 & 26.3 \\
\hline Chile & 1.0 & 1.2 & 0.4 & 0.5 & 38.9 & 37.3 \\
\hline Poland & 2.1 & 3.3 & 0.5 & 1.2 & 34.7 & 38.8 \\
\hline Mexico & 1.1 & 2.4 & 1.4 & 2.2 & 37.0 & 36.9 \\
\hline Malaysia & 0.5 & 1.1 & 0.5 & 0.8 & 38.9 & 40.1 \\
\hline Thailand & 2.0 & 2.8 & 0.9 & 1.3 & 38.0 & 38.6 \\
\hline Indonesia & 2.2 & 4.5 & 0.5 & 1.8 & 31.8 & 31.1 \\
\hline India & 0.7 & 0.9 & 0.4 & 0.6 & 33.6 & 40.9 \\
\hline Average & 1.6 & 2.9 & 0.5 & 1.1 & 39.0 & 38.7 \\
\hline High & 18.3 & 32.7 & 3.6 & 8.4 & 47.3 & 47.1 \\
\hline Low & 0.1 & 0.2 & 0.1 & 0.1 & 31.8 & 26.3 \\
\hline
\end{tabular}

Table 2: Absolute average error, volatility and risk ratings 


\section{A simple theoretical approach to public and private information}

Here I describe how transparency might have either a positive or negative effect on predictability in a very general but formal way. Along the lines of the dataset employed below, consider a number of central banks, each with an accompanying set of professional forecasters who make predictions of future policy rates.

A simple way to think about individual forecasts is as combinations of public and private information, which are both noisy signals of future policy rates. The noise in the signals are random errors that are assumed to be unbiased and independently normally distributed. In the context of the data used, these signals have a year index, $t$, but I suppress the subscript in this section because it applies to all variables.

$$
y_{k}=b_{k}+\omega_{k} \quad \omega_{k}=\mathrm{N}\left(0, \frac{1}{\sqrt{\Delta_{k}}}\right)
$$

Where

$y \quad$ public signal

$b$ future policy rate

$\omega_{k} \quad$ error of public signal for country $k$

$k$ country index

$\Delta$ precision of public signal error (i.e. inverse of the variance)

$$
p_{i, k}=b_{k}+\omega_{i, k} \quad \omega_{i, k}=\mathrm{N}\left(0, \frac{1}{\sqrt{s_{i, k}}}\right)
$$

Where

$$
\begin{array}{ll}
p_{i, k} & \text { private signal of forecaster } i \text { for country } k \\
i & \text { forecaster index } \\
\omega_{i, k} & \text { error of private signal of forecaster } i \text { for country } k \\
s_{i, k} & \text { precision of private signal error (i.e. inverse of the variance) }
\end{array}
$$

Assuming the forecaster aims to maximize accuracy, knows the precisions of the public and private signals, and behaves rationally, the individual forecast, $f_{i, k}$, will be a combination of private and public signals, using relative precisions as weights.

$$
f_{i, k}=\frac{\Delta_{k}}{\Delta_{k}+s_{i, k}} y+\frac{s_{i, k}}{\Delta+s_{i, k}} p_{i, k}
$$

The error of the individual forecast with the future interest rate, $\xi_{i, k}$, is derived by subtracting $b$ from the forecast. 


$$
\xi_{i, k}=f_{i, k}-b_{k}=\frac{\Delta_{k}}{\Delta_{k}+s_{i, k}} \omega_{k}+\frac{s_{i, k}}{\Delta+s_{i, k}} \omega_{i, k}
$$

A convenient property of signals with normally and independently distributed errors is that the combined signal has a precision that is the sum of the precisions of the individual signals. Equation (5) thus represents the precision of the forecast error, $\zeta_{i, k}$.

$$
\zeta_{i, k}=\Delta_{k}+s_{i, k}
$$

It seems likely that transparency will increase the precision of the public information. Equation (6) defines $\Delta_{k}$ to be a function of transparency $(\tau)$ and some other determinants $D_{k}$.

$$
\Delta_{k}=\phi_{\Delta}\left(+\tau, D_{k}\right)
$$

Where

$\tau \quad$ transparency

$D_{k} \quad$ vector of other determinants of the precision of public information

It is less clear if transparency will affect private information. In Equation (4) the weight on public information will increase as it becomes more precise and the weight on private information will decline, while the precision of private information will remain unchanged. It may be the case, however, that the precision itself is also affected. In line with the reasoning of Morris and Shin (2002), agents may partially ignore their own private information because the public signal acts as a coordinator of second degree expectations and thus becomes over-emphasized in determining the resale value of the asset. Kool et al. (2011) also raise the possibility that when private information is costly individual forecasters will invest less in the precision of the private signal. Both cases imply a negative relationship between transparency and private information.

$$
s_{i, k}=\phi_{s}\left(-\tau, D_{i, k}\right)
$$

As a result, the relationship between transparency and predictability will be a function of transparency's separate effects on the public and private signals.

$$
\zeta_{i, k}=\phi_{\Delta}\left(+\tau, D_{k}\right)+\phi_{s}\left(-\tau, D_{i, k}\right)
$$

Kool et al. (2011) show that in a rational expectations asset market the affect of transparency on volatility is theoretically the same as its affect on predictability. They show that transparency can crowd out private information and thereby both hurt predictability and push up volatility.

It is quite possible that in order to closely model the relationship between transparency and the precisions of private and public information a more complex setup would be required. For example, to represent the idea of Dale et al. (2008) that forecasters may misestimate the precision of the public signal would 
require adjusting the above equations to make a distinction between the actual precisions and those that the forecasters perceive and thus use as weights. Furthermore, Berger et al. (2006) note that forecasters differ in their analysis of public information, indicating some complementaries between public and private data. More generally, the approach used here requires assuming rational agents that are able to optimally combine information, precluding the type of confusion from multiple signals found in Ehrmann and Fratzscher (2007). These papers indicate that the simple approach employed here leaves many paths unexplored. However, it is not my intention to construct a unifying theoretical model that could incorporate all potential adverse effects of greater transparency. Instead my goal is to provide a basic theoretical benchmark for interpreting the econometric results presented in the next section.

\section{Evidence}

Below I present regression results for the relationship between transparency and forecaster errors, followed by similar analysis for transparency's impact on interest rate volatility. First, however, I present two graphs to illustrate the cross-country relationship of transparency with both forecast accuracy and volatility. Both the graphs and the econometric evidence point to the conclusion that transparency helps to improve accuracy and reduce volatility.

\subsection{Cross section graphs}

Graphs offer an intuitive way to illustrate the consequences of transparency for predictability and interest rate volatility. Their downside is that any relationship that is visually apparent may not stand the scrutiny of econometric analysis. However, as I present such analysis in subsequent sections, it is a useful first step to show that at least the superficial relationships one would expect are present in the cross-section of the data. Assuming that negative effects of transparency on private information do not dominate, countries with higher transparency should have lower absolute forecast errors and lower interest rate volatility. Indeed, that is what the scatter plots presented in Figures 5 and 6 suggest.

The graphs show a dot for each country in the sample except Argentina, which has average errors and volatility well above that of the other countries (See Table 2). Rather than looking at a specific year, the levels of transparency, forecast errors and volatility are averaged over the five years of the sample. I focus on the 3-month forecasts and volatilities. The black lines represent ordinary least squares linear regressions fitted on the datapoints shown. 


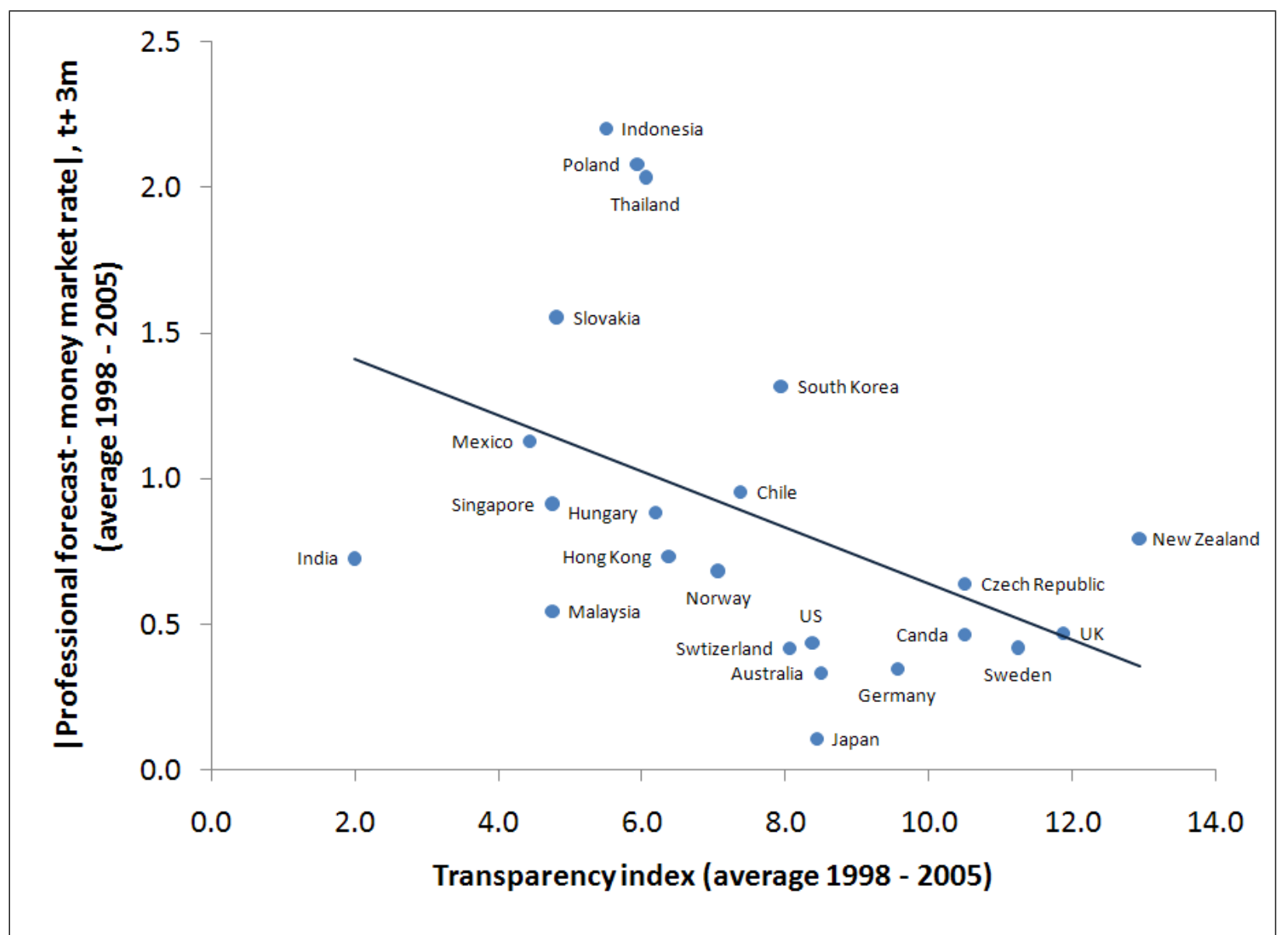

Figure 5: Transparency and forecast accuracy, country cross section 


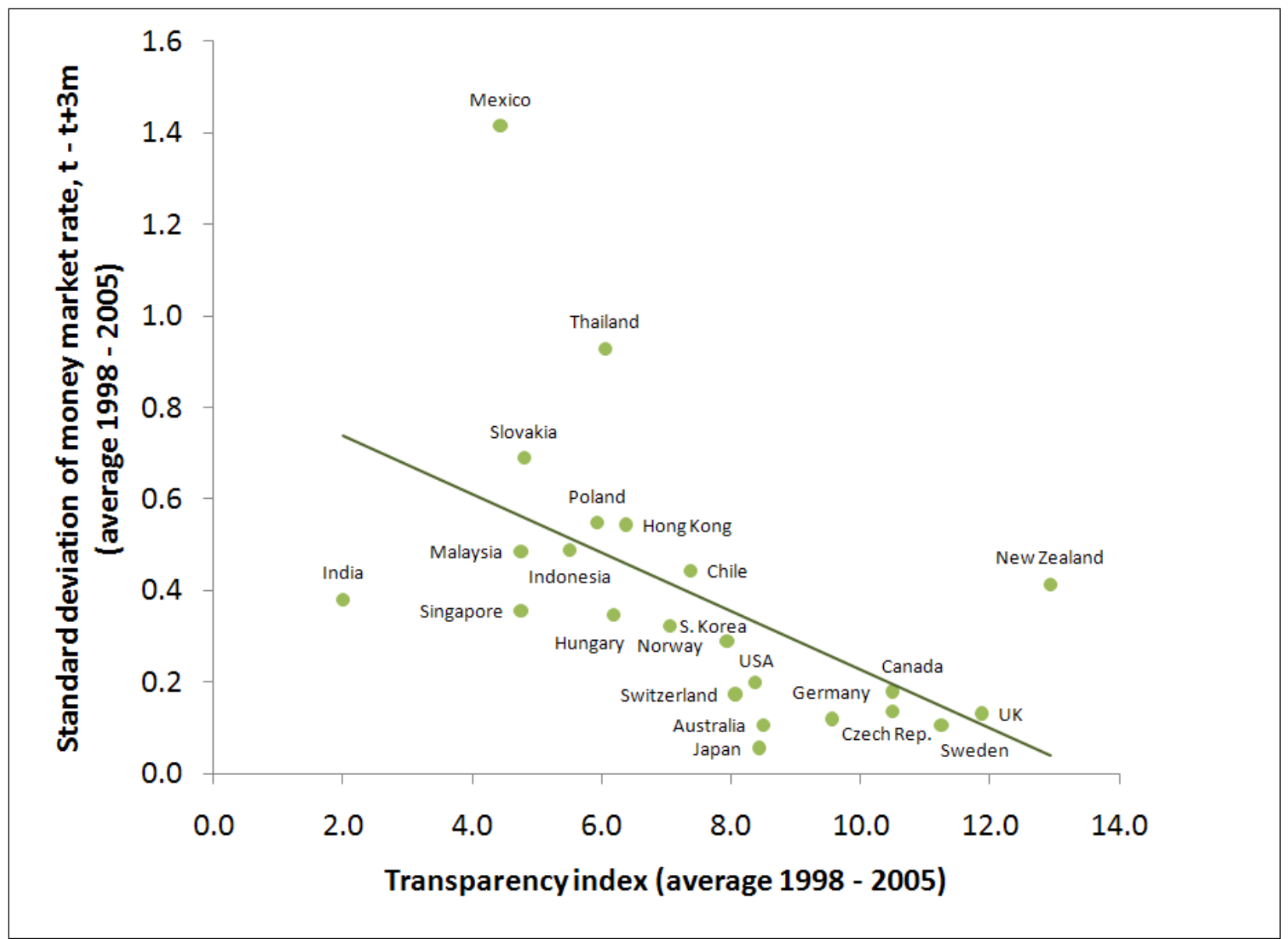

Figure 6: Transparency and interest rate volatility, country cross-section

\subsection{Forecast accuracy}

Having illustrated graphically that the cross-section shows a negative relationship between transparency and both forecast errors and interest rate volatility, the next step is to utilize the full panel for a more complete econometric analysis that controls adequately for country features other than central bank transparency. This section does this for forecast errors and the next one for interest rate volatility.

The results shown below are obtained from the following panel regression for the individual forecast errors. 


$$
\left|\begin{array}{l}
m \\
\xi \\
i, k, t
\end{array}\right|=\beta \tau_{k, t}+\beta e_{k, t}+\beta l_{k, t}+\beta d_{i, k, t}+c+\varepsilon_{i, k, t}
$$

Where

$\begin{array}{ll}\xi & \text { forecast error } \\ m & \text { forecast months ahead }(3,12) \\ k & \text { country index } \\ i & \text { forecaster index } \\ t & \text { time index }(1998,1999 \ldots \\ \beta & \text { parameters to estimate } \\ \tau & \text { transparency index } \\ e & \text { PRS economic risk rating } \\ l & \text { PRS financial risk rating } \\ d & \text { forecaster dummy } \\ c & \text { constant } \\ \varepsilon & \text { regression error }\end{array}$

Most of equation (9) is a straightforward incorporation of the variables discussed in Section 1. The absolute error of the individual forecasts is the dependent variable. The transparency index and the risk indices are the main independent variables. Forecaster fixed effects are used because the Breusch and Pagan Lagrangian multiplier test for random effects clearly rejects the null hypothesis of random effects ( $p$-value $=0.0000$ ) regardless of whether or not time dummies are also included in the regression. Time dummies are not included because the Wald test does not find them to be jointly significant ( $\mathrm{p}$-value $=$ 0.1483). The specification tests are based on the regression on the three month forecast error with the entire sample.

Because it is likely that the individual forecaster errors are correlated within a country, I use robust standard errors that correct for such clustering. The consequences are substantial. The correction roughly triples the standard error for the transparency index. ${ }^{6}$

The output from the regression in Equation (9) is presented in Table 4. Results are shown for both the $t+3$ month and $t+12$ forecast errors and for both the full sample and several sub-samples based on geography and income level. A per capita GDP at PPP of $\$ 25000$ is the best point to split the sample because it creates approximately equally sized samples and there is a significant gap in income between the two countries on either side of the split (see Table 1). An overview of the countries included in the samples is provided in Table 3.

\footnotetext{
${ }^{6}$ Errors may also be correlated within organizations across countries, when international organizations provide forecasts for several countries. I examined a correction for this and found that the results were essentially identical and thus I do not use it in the results presented.
} 


\begin{tabular}{|l|c|c|}
\hline & GDP per capita > \$25k & GDP per capita < \$25k \\
\hline Asia-Pacific & $\begin{array}{c}\text { Australia, Hong Kong, } \\
\text { Japan, Singapore }\end{array}$ & $\begin{array}{c}\text { India, Indonesia, Malaysia, N. } \\
\text { Zealand, S. Korea, Thailand }\end{array}$ \\
\hline Europe & $\begin{array}{c}\text { Germany, Norway, Sweden, } \\
\text { Switzerland, UK }\end{array}$ & $\begin{array}{c}\text { Czech Republic, Hungary, } \\
\text { Poland, Slovakia }\end{array}$ \\
\hline Americas & Canada, USA & Argentina, Chile, Mexico \\
\hline
\end{tabular}

Table 3: Sample matrix

Overall the results in Table 4 suggest that higher monetary policy transparency is effective in improving predictability of money market rates three months into the future. The full sample regression indicates an average $0.3 \%$ point reduction in the $t+3$ month absolute forecast error. The reduction is not only statistically significant, but also economically significant considering the average absolute error of 1.6\%-point reported in Table 2. Results vary somewhat across the sub-samples. The impact of transparency is negative in all of the samples, but not significant in the case of countries with lower per capita income and the Americas. Insignificance there is the result of larger standard errors rather than a smaller coefficient, which are similar across all subsamples except for the Americas. The latter is affected by the large forecast errors for Argentina in a small sample of only five countries. The overall results, however, are not substantively altered by removing Argentina, although the coefficient for the low income sample becomes marginally significant (See Table 5). 


\begin{tabular}{|c|c|c|c|c|c|}
\hline \multicolumn{6}{|l|}{$t+3 m$ forecast error } \\
\hline & \multicolumn{2}{|l|}{ full sample } & \multicolumn{2}{|l|}{ GDP per capita $>25 \mathrm{k}$} & GDP per capita $<25 \mathrm{k}$ \\
\hline & coeff. $\quad p$ & & coeff. $\mathrm{p}$ & & coeff. $p$ \\
\hline transparency & -0.300 .03 & $* *$ & $-0.210 .02 *$ & ** & $\begin{array}{lll}-0.30 & 0.23\end{array}$ \\
\hline PRS financial risk index & -0.250 .13 & & -0.010 .73 & & -0.390 .15 \\
\hline PRS economic risk index & -0.300 .12 & & -0.010 .50 & & -0.380 .15 \\
\hline $\mathrm{c}$ & 25.020 .07 & $*$ & $3.190 .05 *$ & $* *$ & $32.070 .08 *$ \\
\hline $\mathrm{R}^{2}$ & 0.17 & & 0.10 & & 0.27 \\
\hline countries & 24 & & 11 & & 13 \\
\hline \multirow[t]{3}{*}{ observations } & 2236 & & 1308 & & 928 \\
\hline & $\underline{\text { Asia-Pacific }}$ & & Europe & & Americas \\
\hline & coeff. $\quad \mathrm{p}$ & & coeff. $\quad \mathrm{p}$ & & coeff. $\mathrm{p}$ \\
\hline transparency & -0.390 .04 & $* *$ & $-0.210 .05 *$ & * & -9.550 .31 \\
\hline PRS financial risk index & -0.190 .06 & $*$ & 0.000 .95 & & $\begin{array}{ll}-0.93 & 0.24\end{array}$ \\
\hline PRS economic risk index & $-0.08 \quad 0.21$ & & $-0.070 .07 *$ & * & $-0.03 \quad 0.93$ \\
\hline $\mathrm{c}$ & 14.240 .01 & $* * *$ & $5.470 .06 *$ & * & 113.230 .23 \\
\hline $\mathrm{R}^{2}$ & 0.33 & & 0.27 & & 0.20 \\
\hline countries & 10 & & 9 & & 5 \\
\hline observations & 895 & & 885 & & 444 \\
\hline
\end{tabular}

\begin{tabular}{|c|c|c|c|c|c|}
\hline \multicolumn{6}{|l|}{$t+12 m$ forecast error } \\
\hline & \multicolumn{2}{|l|}{ full sample } & GDP per capita $>25 \mathrm{k}$ & \multicolumn{2}{|l|}{$\underline{\text { GDP per capita }<25 \mathrm{k}}$} \\
\hline & coeff. $\quad \mathrm{p}$ & & coeff. $p$ & coeff. $p$ & \\
\hline transparency & -0.410 .23 & & -0.070 .58 & -0.600 .36 & \\
\hline PRS financial risk index & -0.280 .04 & $* *$ & -0.060 .17 & -0.460 .12 & \\
\hline PRS economic risk index & -0.250 .06 & $*$ & 0.050 .46 & $-0.290 .04 *$ & $* *$ \\
\hline $\mathrm{c}$ & 25.920 .02 & $* *$ & 1.950 .59 & $34.530 .02 *$ & $* *$ \\
\hline $\mathrm{R}^{2}$ & 0.16 & & 0.07 & 0.22 & \\
\hline countries & 24 & & 11 & 13 & \\
\hline \multirow[t]{3}{*}{ observations } & 2191 & & 1291 & 900 & \\
\hline & $\underline{\text { Asia-Pacific }}$ & & Europe & Americas & \\
\hline & coeff. $\quad p$ & & coeff. $\quad \mathrm{p}$ & coeff. $\quad \mathrm{p}$ & \\
\hline transparency & -0.230 .06 & $*$ & -0.020 .90 & -4.500 .25 & \\
\hline PRS financial risk index & -0.330 .01 & $* * *$ & -0.150 .13 & $-0.48 \quad 0.24$ & \\
\hline PRS economic risk index & -0.090 .35 & & $-0.320 .03 * *$ & $-0.920 .08 *$ & * \\
\hline $\mathrm{c}$ & 19.720 .00 & $* * *$ & $20.600 .01 \quad * * *$ & $90.800 .10 *$ & $*$ \\
\hline $\mathrm{R}^{2}$ & 0.29 & & 0.19 & 0.23 & \\
\hline countries & 10 & & 9 & 5 & \\
\hline observations & 867 & & 880 & 456 & \\
\hline
\end{tabular}

Table 4: Transparency and forecast errors 


\begin{tabular}{|c|c|c|c|}
\hline \multicolumn{4}{|l|}{$t+3 m$ forecast error } \\
\hline & $\underline{\text { full sample }}$ & & GDP per capita $<25 \mathrm{k}$ \\
\hline & coeff. $\quad \mathrm{p}$ & & coeff. $\quad p$ \\
\hline transparency & -0.270 .01 & $* *$ & $-0.290 .09 *$ \\
\hline PRS financial risk index & -0.090 .09 & $*$ & -0.140 .12 \\
\hline PRS economic risk index & -0.110 .03 & $* *$ & $-0.150 .10 *$ \\
\hline $\mathrm{c}$ & 10.920 .00 & $* * *$ & $13.900 .00 * * *$ \\
\hline $\mathrm{R}^{2}$ & 0.24 & & 0.28 \\
\hline countries & 23 & & 12 \\
\hline observations & 2203 & & 895 \\
\hline \multicolumn{4}{|l|}{$t+12 m$ forecast error } \\
\hline & full sample & & GDP per capita $<25 \mathrm{k}$ \\
\hline & coeff. $\quad p$ & & coeff. $p$ \\
\hline transparency & -0.140 .26 & & -0.110 .52 \\
\hline PRS financial risk index & $-0.18 \quad 0.02$ & $* *$ & -0.230 .13 \\
\hline PRS economic risk index & -0.160 .06 & $*$ & $-0.270 .02 * *$ \\
\hline $\mathrm{c}$ & 15.890 .00 & $* * *$ & $21.270 .00 * * *$ \\
\hline $\mathrm{R}^{2}$ & 0.23 & & 0.35 \\
\hline countries & 23 & & 12 \\
\hline observations & 2166 & & 875 \\
\hline
\end{tabular}

Table 5: Transparency and forecast errors, without Argentina

Regarding the $t+12$ month forecast errors, results do not warrant the conclusion that transparency improves predictability. The estimated impact of transparency is greater for the complete sample and some of the subsamples unless Argentina is removed. In any case, the larger standard errors mean the estimates are not statistically significant except for the Asia-Pacific region.

The fit of the regression tends to be best for the samples that contain fewer advanced countries. The best explanation for this is that the PRS risk indices are better at explaining forecast errors for these countries. Considering that overall economic and financial risk is probably a more important factor in these countries, this makes sense. The significance of the PRS risk indices is somewhat obscured, however, by the $50 \%$ correlation of the economic and finance indicators. As result they are not separately significant in many cases, but do have better joint significance.

Overall, the results both support and expand the conclusion of earlier empirical research that transparency improves predictability. The approach here 
improves on earlier research by actually measuring the relationship between a transparency index and predictability, so that it is possible to say how much transparency leads to how much predictability. It adds to the robustness of the conclusion by confirming it across a variety of countries. Although the effect is only weakly significant for the low income sample without Argentina, the consistency of the coefficient suggests that it does apply to most countries, but cannot be established as strongly significant due to the larger standard errors.

The difference between transparency's effect on predictability on the three month and twelve month forecast horizons suggests potential limits to the benefits of transparency. It seems plausible that any information asymmetries between policy makers and professional forecasters are likely to be greatest in the short term where the former group has, at the very least, a unique insight into their own views about incoming data and the economic outlook. As I find, greater transparency thus has more potential to improve the precision of public information at shorter timeframes. At longer forecast horizons such information asymmetries are less obvious as the economic future becomes cloudier for all. It is thus not surprising to find that evidence of improved transparency at the twelve month forecast horizon is very weak and inconsistent across samples. It is possible, however, that there is some scope for central banks to share information about the longer term outlook that has not been fully utilized.

\subsection{Interest rate volatility}

A potential benefit of improved monetary policy predictability is that it may lead to lower interest rate volatility. To examine the connection between transparency and interest rate volatility, I conduct a similar panel regression analysis with interest rate volatility.

$\left|\begin{array}{l}m \\ \sigma_{k, t}\end{array}\right|=\beta \tau_{k, t}+\beta e_{k, t}+\beta l_{k, t}+\beta d_{k, t}+c+\varepsilon_{i, k, t}$

Where

$\sigma \quad$ standard deviation of daily money market rates, from $t$ to $t+m$

While the dependent variable is now a measure of interest rate volatility, the independent variables in Equation (10) are the same as in Equation (9). As above, the Breusch and Pagan test rejects the random effects specification, both with and without time fixed effects ( $\mathrm{p}$-value of 0.0068 and 0.0085 respectively). The Wald test rejects the joint significance of the time dummies (p-value of 0.1345), so no time fixed effects are included. 


\begin{tabular}{|c|c|c|c|c|c|}
\hline \multicolumn{6}{|c|}{$t+3 m$ daily standard deviation of $3 \mathrm{~m}$ interest rate } \\
\hline \multirow[b]{3}{*}{ transparency } & \multirow{2}{*}{$\frac{\text { full sample }}{\text { coeff. } \quad p}$} & & GDP per capita $>25 \mathrm{k}$ & \multicolumn{2}{|l|}{ GDP per capita $<25 \mathrm{k}$} \\
\hline & & & coeff. $\mathrm{p}$ & coeff. $p$ & \\
\hline & -0.110 .10 & & $-0.120 .00 * * *$ & -0.130 .26 & \\
\hline PRS financial risk index & $\begin{array}{lll}-0.08 & 0.23\end{array}$ & & 0.010 .58 & -0.140 .21 & \\
\hline PRS economic risk index & -0.090 .12 & & $-0.05 \quad 0.25$ & -0.060 .45 & \\
\hline $\mathrm{c}$ & 7.970 .04 & $* *$ & 2.810 .10 & 8.890 .05 & $*$ \\
\hline $\mathrm{R}^{2}$ & 0.51 & & 0.39 & 0.50 & \\
\hline countries & 24 & & 11 & 13 & \\
\hline \multirow[t]{3}{*}{ observations } & 172 & & 88 & 84 & \\
\hline & $\underline{\text { Asia-Pacific }}$ & & Europe & Americas & \\
\hline & coeff. $\quad \mathrm{p}$ & & coeff. $\quad \mathrm{p}$ & coeff. $\quad p$ & \\
\hline transparency & -0.140 .00 & $* * *$ & $-0.140 .02 * *$ & -1.750 .00 & $* * *$ \\
\hline PRS financial risk index & -0.040 .24 & & 0.060 .29 & -0.240 .18 & \\
\hline PRS economic risk index & -0.010 .61 & & $0.00 \quad 0.91$ & -0.330 .06 & $*$ \\
\hline $\mathrm{c}$ & 3.500 .00 & $* * *$ & -0.960 .74 & $36.080 .00=$ & $* * *$ \\
\hline $\mathrm{R}^{2}$ & 0.55 & & 0.27 & 0.91 & \\
\hline countries & 10 & & 9 & 5 & \\
\hline observations & 80 & & 64 & 28 & \\
\hline
\end{tabular}

\begin{tabular}{|c|c|c|c|}
\hline \multicolumn{4}{|c|}{$\mathbf{t}+12 \mathrm{~m}$ daily standard deviation of $3 \mathrm{~m}$ interest rate } \\
\hline \multirow[b]{3}{*}{ transparency } & \multirow{3}{*}{ 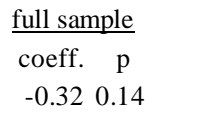 } & GDP per capita $>25 \mathrm{k}$ & GDP per capita $<25 \mathrm{k}$ \\
\hline & & coeff. $\mathrm{p}$ & coeff. $\mathrm{p}$ \\
\hline & & $-0.100 .01 * *$ & -0.130 .26 \\
\hline PRS financial risk index & -0.090 .24 & $-0.03 \quad 0.10$ & -0.140 .21 \\
\hline PRS economic risk index & -0.090 .31 & -0.050 .16 & -0.060 .45 \\
\hline $\mathrm{c}$ & $10.680 .02 * *$ & $4.480 .01 * * *$ & $8.890 .05 *$ \\
\hline $\mathrm{R}^{2}$ & 0.51 & 0.52 & 0.50 \\
\hline countries & 24 & 11 & 13 \\
\hline \multirow[t]{3}{*}{ observations } & 172 & 88 & 84 \\
\hline & $\underline{\text { Asia-Pacific }}$ & Europe & $\underline{\text { Americas }}$ \\
\hline & coeff. $\quad \mathrm{p}$ & coeff. $p$ & coeff. $\quad \mathrm{p}$ \\
\hline transparency & -0.320 .14 & $-0.100 .01 * *$ & -0.490 .21 \\
\hline PRS financial risk index & -0.120 .13 & -0.020 .62 & -0.510 .21 \\
\hline PRS economic risk index & -0.070 .40 & $-0.140 .02 * *$ & 0.640 .22 \\
\hline $\mathrm{c}$ & $9.090 .05 * *$ & $7.980 .01 * * *$ & $45.990 .00 * * *$ \\
\hline $\mathrm{R}^{2}$ & 0.46 & 0.51 & 0.82 \\
\hline countries & 10 & 9 & 5 \\
\hline observations & 80 & 64 & 28 \\
\hline
\end{tabular}

Table 6: Transparency and forecast volatility 
Results for the entire sample suggest that transparency does not have a significant impact on the standard deviation of interest rates for the $t$ to $t+3$ period. However, all but one of the subsamples shows a significant impact. The size of the estimated effect is similar across all subsamples, except for the Americas subsample, where the estimate is probably largely driven by the high volatility of Argentina's interest rates in a small sample. The estimates for the entire sample and the subsamples are also economically meaningful considering the average standard deviation of $0.5 \%$-point reported in Table 2 .

The evidence for the impact of transparency on the standard deviation of interest rates for the $t$ to $t+12$ period is weaker. Results are only significant for high income countries and Europe subsamples. There the reduction in volatility is similar in scale to the results for the $t$ to $t+3$ period.

Unlike the results for the forecast errors, removing Argentina from the sample has a substantial impact on the significance of the results.

\begin{tabular}{|c|c|c|c|}
\hline \multicolumn{4}{|c|}{ t+3m daily standard deviation of $3 \mathrm{~m}$ interest rate } \\
\hline & full sample & & $\underline{\text { GDP per capita }<25 \mathrm{k}}$ \\
\hline & coeff. $\quad \mathrm{p}$ & & coeff. $\mathrm{p}$ \\
\hline transparency & -0.140 .00 & $* * *$ & $-0.160 .00 * * *$ \\
\hline PRS financial risk index & 0.000 .96 & & -0.020 .68 \\
\hline PRS economic risk index & -0.030 .12 & & -0.010 .70 \\
\hline $\mathrm{c}$ & 2.710 .00 & $* * *$ & $2.770 .02 * *$ \\
\hline $\mathrm{R}^{2}$ & 0.37 & & 0.29 \\
\hline countries & 23 & & 12 \\
\hline observations & 168 & & 80 \\
\hline \multicolumn{4}{|c|}{$\mathbf{t}+\mathbf{1 2 m}$ daily standard deviation of $3 \mathrm{~m}$ interest rate } \\
\hline & full sample & & $\underline{\text { GDP per capita }<25 \mathrm{k}}$ \\
\hline & coeff. $\quad \mathrm{p}$ & & coeff. $p$ \\
\hline transparency & -0.110 .03 & $* *$ & -0.110 .28 \\
\hline PRS financial risk index & -0.070 .14 & & -0.080 .38 \\
\hline PRS economic risk index & -0.100 .17 & & -0.110 .37 \\
\hline $\mathrm{c}$ & 8.200 .03 & $* *$ & $8.660 .04 * *$ \\
\hline $\mathrm{R}^{2}$ & 0.46 & & 0.40 \\
\hline countries & 23 & & 12 \\
\hline observations & 168 & & 80 \\
\hline
\end{tabular}

Table 7: Transparency and interest rate volatility, without Argentina 
Without Argentina, the full sample results are clearly significant for both the three month and twelve month volatility measures. The three month volatility measure for the low income countries is also highly significant.

As noted in the section on data, the time frames of the volatility measure are, in practice, somewhat different than that of the forecast errors, helping to explain why the coefficients for three and twelve month volatility are closer together than for the forecast errors. Nevertheless, the overall pattern runs parallel to that of the forecast errors: transparency reduces volatility and the reduction is greater at a shorter time frame and fades over a longer time frame. The theoretical prediction, presented in the Section 2, that transparency, predictability and market stability are closely related is therefore supported by these results. Likewise, the purported benefit of transparency at fostering financial market stability is supported by the evidence presented above.

\section{Conclusion}

Central bankers have sought to improve the predictability of monetary policy as a way to reduce interest rate volatility and thereby enhance economic stability. While some theoretical and experimental papers, including contributions by the author, suggest that central bank transparency might actually harm predictability by hampering the use of private information, most empirical work has found these concerns to be unwarranted. Such research, however, has generally only compared average predictability before and after some watershed transparency reform and done so only for a limited number of advances economies. My approach has a broader scope because I examine the relationship between the Dincer and Eichengreen transparency index and predictability for twentyfour countries with varying levels of income. Furthermore, I use professional forecasts, which have seen limited use in multi-country predictability analysis. Finally, I also examine interest rate volatility, to see if predictability and transparency do indeed go hand-in-hand, something which is not extensively done in the literature.

The results provide improved empirical evidence that supports the general finding that transparency is beneficial and does so for a broad set of countries. Forecast errors decline significantly for the three month ahead forecasts, although not at the horizon of one year. My evidence also suggests that the volatility of interest rates do indeed track predictability. Greater transparency is accompanied by a significant decline in interest rate volatility. 


\section{References}

Bauer, A., Eisenbeis, R., Waggoner, D. and Zha, T.: 2006, Transparency, expectations and forecasts. Federal Reserve Bank of Atlanta Working Paper 2006-3.

Berger, H., Ehrmann, M. and Fratzscher, M.: 2006, Forecasting ECB monetary policy: Accuracy is (still) a matter of geography? ECB Working Paper No. 578.

Bernanke, B.: 2004, Central bank talk and monetary policy. Speech, 7 October.

Blinder, A., Ehrmann, M., Fratzscher, M., de Haan, J. and Jansen, D.-J.: 2008, Central bank communication and monetary policy: A survey of theory and evidence. CEPS Working Paper.

Campbell, J. Y. and Shiller, R. J.: 1991, Yield spreads and interest rate movements: A bird's eye view, The Review of Economic Studies 58(3), 495-514.

Carlson, J., Craig, B., Higgins, P. and Melick, W.: 2006, FOMC communications and the predictability of near-term policy decisions. Federal Reserve of Cleveland Review.

Cecchetti, S. G. and Hakkio, C.: 2009, Inflation targeting and private sector forecasts. NBER Working Paper No. 15424.

Cochrane, J. H. and Piazzesi, M.: 2005, Bond risk premia, American Economic Review 95(1), 138-160.

Coppel, J. and Connolly, E.: 2003, What do financial market data tell us about monetary policy transparency? Reserve Bank of Australia Working Paper.

Crowe, C.: 2006, Testing the transparency benefits of : Evidence from private sector forecasts. IMF Working Paper 06/289.

Crowe, C. and Meade, E. E.: 2008, Central bank independence and transparency: Evolution and effectiveness. IMF Working Paper 08/119.

Dale, S., Orphanides, A. and Osterholm, P.: 2008, Imperfect central bank communication - information vs. distraction. IMF Working Paper 08/60.

Demertzis, M. and Hoeberichts, M.: 2007, The costs of increasing transparency, Open Economies Review 18, 263-280.

Dincer, N. and Eichengreen, B.: 2007, Central bank transparency: Where, why and with what effects? NBER Working Paper No. 13003.

Ehrmann, M., Eijffinger, S. and Fratzscher, M.: 2010, The role of central bank transparency for guiding private sector forecasts. ECB Working Paper No. 1146. 
Ehrmann, M. and Fratzscher, M.: 2007, Social value of public information: Testing the limits of transparency. ECB Working Paper No. 821.

Eijffinger, S. and Geraats, P.: 2006, How transparent are central banks?, European Journal of Political Economy 22, 1-21.

Fama, E. F. and Bliss, R. R.: 1987, The information in long-maturity forward rates, The American Economic Review 77(4), 680-692.

Hayford, M. and Malliaris, A.: 2007, Transparent monetary policy. Loyola University Chicago Working Paper.

Hayo, B. and Neuenkirch, M.: 2009, Does FOMC communication help predicting federal funds target rate changes? MAGKS Joint Discussion Paper Series in Economics, No. 25-2009.

Holmsen, A., Qvigstad, J. F., Øistein Røisland and Solberg-Johansen, K.: 2008, Communicating monetary policy intentions: The case of Norges Bank. Norges Bank Working Paper 2008-20.

Jansen, D.-J. and de Haan, J.: 2009, Has ECB communication been helpful in predicting interest rate decisions? an evaluation of the early years of the economic and monetary union, Applied Economics 41(16), 1995-2003.

Johnson, D.: 2002, The effect of inflation targeting on the behavior of expected inflation, Journal of Monetary Economics 49, 1521-1538.

Kool, C., Middeldorp, M. and Rosenkranz, S.: 2011, Central bank transparency and the crowding out of information in the financial markets, Journal of Money, Credit and Banking. Forthcoming.

Kwan, S.: 2007, On forecasting future monetary policy: Has forward-looking language mattered? Federal Reserve Bank of San Francisco Economic Letter 2007-15.

Lange, J., Sack, B. and Whitesell, W.: 2003, Anticipations of monetary policy in financial markets, Journal of Money, Credit and Banking 35(6), 889-909.

Lildholdt, P. and Wetherilt, A. V.: 2004, Anticipation of monetary policy in UK financial markets. Bank of England Working Paper 241.

Linder, A. and Santiso, C.: 2002, Assessing the predictive power of country risk ratings and governance indicators. Paul $\mathrm{H}$. Nitze School of Advanced International Studies of Johns Hopkins University Working Paper WP/02/02.

Mariscal, I. B.-F. and Howells, P.: 2006a, Monetary policy transparency in the UK: The impact of independence and inflation targeting. University of West England, Bristol Working Paper. 
Mariscal, I. B.-F. and Howells, P.: 2006b, Monetary policy transparency, lessons from Germany and the Eurozone. University of West England, Bristol Working Paper.

Middeldorp, M.: 2011, FOMC communication policy and the accuracy of Fed funds futures. Federal Reserve Bank of New York Staff Report 491.

Middeldorp, M. and Rosenkranz, S.: 2011, Central bank communication and the crowding out of private information in an experimental asset market. Federal Reserve Bank of New York Staff Report 487.

Mizen, P.: 2009, What can we learn from central bankers' words? some nonparametric tests for the ECB, Economic Letters 103, 29-32.

Morris, S. and Shin, H. S.: 2002, Social value of public information, The American Economic Review 92(5), 1521-1534.

Murdzhev, A. and Tomljanovich, M.: 2006, What is the color of Alan Greenspan's tie? how central bank policy announcements have changed financial markets, Eastern Economic Journal 32(4).

Piazzesi, M. and Swanson, E.: 2008, Futures prices as risk-adjusted forecasts of monetary policy, Journal of Monetary Economics 55, 677-691.

Rafferty, M. and Tomljanovich, M.: 2002, Central bank transparency and market efficiency: An econometric analysis, Journal of Economics and Finance 26(2), 150-161.

Sack, B.: 2004, Extracting the expected path of monetary policy from futures rates, The Journal of Futures Markets 24(8), 733-754.

Stambaugh, R. F.: 1988, The information in forward rates, Journal of Financial Economics 21, 41-70.

Sturm, J.-E. and de Haan, J.: 2009, Does central bank communication really lead to better forecasts of policy decisions? new evidenced based on a Taylor rule model for the ECB. KOF Working Paper 2009 No. 236.

Svensson, L. E.: 2006, Social value of public information: Morris and shin (2002) is actually pro transparency, not con, The American Economic Review 96(1), 448-452.

Swanson, E.: 2006, Have increases in Federal Reserve transparency improved private sector interest rate forecasts, Journal of Money, Credit and Banking 38, $792-819$.

Tomljanovich, M.: 2004, Does central bank transparency impact financial markets? a cross country econometric analysis, Southern Economic Journal

van der Cruijsen, C. and Eijffinger, S.: 2007, The economic impact of central bank transparency: A survey. CEPR Working Paper No. 6070. 


\section{APPENDIX - Transparency Checklist}

Text copied directly from Appendix of Dincer and Eichengreen (2007)

This appendix describes the construction of the transparency index. The index is the sum

of the scores for answers to the fifteen questions below $(\min =0$, $\max =15)$.

1. Political Transparency

Political transparency refers to openness about policy objectives. This comprises a formal statement of objectives, including an explicit prioritization in case of multiple goals, a quantification of the primary objective(s), and explicit institutional arrangements.

(a) Is there a formal statement of the objective(s) of monetary policy, with an explicit prioritization in case of multiple objectives?

No formal objective(s) $=0$.

Multiple objectives without prioritization $=1 / 2$.

One primary objective, or multiple objectives with explicit priority $=1$.

(b) Is there a quantification of the primary objective(s)?

$$
\begin{aligned}
& \text { No }=0 . \\
& \text { Yes }=1 .
\end{aligned}
$$

(c) Are there explicit contacts or other similar institutional arrangements between the monetary authorities and the government?

No central bank contracts or other institutional arrangements $=0$.

Central bank without explicit instrument independence or contract $=1 / 2$.

Central bank with explicit instrument independence or central bank contract although possibly subject to an explicit override procedure $=1$.

\section{Economic Transparency}

Economic transparency focuses on the economic information that is used for monetary policy. This includes economic data, the model of the economy that the central bank employs to construct forecasts or evaluate the impact of its decisions, and the internal forecasts (model based or judgmental) that the central bank relies on. 
(a) Is the basic economic data relevant for the conduct of monetary policy publicly available? (The focus is on the following five variables: money supply, inflation, GDP, unemployment rate and capacity utilization.)

Quarterly time series for at most two out of the five variables $=0$.

Quarterly time series for three or four out of the five variables $=1 / 2$.

Quarterly time series for all five variables $=1$.

(b) Does the central bank disclose the macroeconomic model(s) it uses for policy analysis?

$$
\begin{aligned}
& \text { No }=0 . \\
& \text { Yes }=1 .
\end{aligned}
$$

(c) Does the central bank regularly publish its own macroeconomic forecasts?

No numerical central bank forecasts for inflation and output $=0$.

Numerical central bank forecasts for inflation and/or output published at less than quarterly frequency $=1 / 2$.

Quarterly numerical central bank forecasts for inflation and output for the medium term (one to two years ahead), specifying the assumptions about the policy instrument (conditional or unconditional forecasts) $=1$.

\section{Procedural Transparency}

Procedural transparency is about the way monetary policy decisions are taken.

(a) Does the central bank provide an explicit policy rule or strategy that describes its monetary policy framework?

$$
\begin{aligned}
& \text { No }=0 . \\
& \text { Yes }=1 .
\end{aligned}
$$

(b) Does the central bank give a comprehensive account of policy deliberations (or explanations in case of a single central banker) within a reasonable amount of time?

No or only after a substantial lag (more than eight weeks) $=0$.

Yes, comprehensive minutes (although not necessarily verbatim or attributed) or explanations (in case of a single central banker), including a discussion of backward and forward-looking arguments $=1$. 
(c) Does the central bank disclose how each decision on the level of its main operating instrument or target was reached? 0 .

No voting records, or only after substantial lag (more than eight weeks) $=$

Non-attributed voting records $=1 / 2$.

Individual voting records, or decision by single central banker $=1$.

\section{Policy Transparency}

Policy transparency means prompt disclosure of policy decisions, together with an explanation of the decision, and an explicit policy inclination or indication of likely future policy actions.

(a) Are decisions about adjustments to the main operating instrument or target announced promptly?

No or only after the day of implementation $=0$.

Yes, on the day of implementation $=1$.

(b) Does the central bank provide an explanation when it announces policy decisions?

No $=0$

Yes, when policy decisions change, or only superficially $=1 / 2$.

Yes, always and including forwarding-looking assessments $=1$.

(c) Does the central bank disclose an explicit policy inclination after every policy meeting or an explicit indication of likely future policy actions (at least quarterly)?

$$
\begin{aligned}
& \text { No }=0 . \\
& \text { Yes }=1 .
\end{aligned}
$$

\section{Operational Transparency}

Operational transparency concerns the implementation of the central bank's policy actions. It involves a discussion of control errors in achieving operating targets and (unanticipated) macroeconomic disturbances that affect the transmission of monetary policy. Furthermore, the evaluation of the macroeconomic outcomes of monetary policy in light of its objectives is included here as well.

(a) Does the central bank regularly evaluate to what extent its main policy operating targets (if any) have been achieved? 
No or not very often (at less than annual frequency) $=0$.

Yes but without providing explanations for significant deviations $=1 / 2$.

Yes, accounting for significant deviations from target (if any); or, (nearly) perfect control over main operating instrument/target $=1$.

(b) Does the central bank regularly provide information on (unanticipated) macroeconomic disturbances that affect the policy transmission process?

No or not very often $=0$.

Yes but only through short-term forecasts or analysis of current macroeconomic developments (at least quarterly) $=1 / 2$.

Yes including a discussion of past forecast errors (at least annually) $=1$.

(c) Does the central bank regularly provide an evaluation of the policy outcome in light of its macroeconomic objectives?

No or not very often (at less than annual frequency) $=0$.

Yes but superficially $=1 / 2$.

Yes, with an explicit account of the contribution of monetary policy in meeting the objectives $=1$. 